\title{
PESQUISA EM TURISMO NO ÂMBITO DOS PROGRAMAS BRASILEIROS DE PÓS-GRADUAÇÃO EM GEOGRAFIA: A PLATAFORMA SUCUPIRA E O BANCO DE TESES E DISSERTAÇÕES DA CAPES COMO FERRAMENTAS METODOLÓGICAS
}

\author{
Christiano Henrique da Silva Maranhão* \\ Francisco Fransualdo de Azevedo**
}

\begin{abstract}
Resumo: Este relato apresenta as principais potencialidades e limites da Plataforma Sucupira e do Banco de teses e dissertações-Capes, no que se refere ao acesso de informações acadêmico-gerenciais e à catalogação digital (teses e dissertações) em nível de pós-graduação stricto sensu no Brasil, a partir da expertise operacionalizada na tese "A digital geográfica do turismo: uma análise teórico-metodológica e conceitual de teses e dissertações, no âmbito dos programas brasileiros de pós-graduação stricto sensu em geografia", defendida em fevereiro de 2017, na Universidade Federal do Rio Grande do Norte. Metodologicamente, trata-se de um relato avaliativo-explicativo, de viés qualitativo. Como principais potencialidades destacam-se: o controle gerencial articulado e a interface digital moderna e didática. Como limite destaca-se a impossibilidade de acesso a todos os trabalhos, na íntegra para download. Conclui-se que a Plataforma Sucupira e o Banco de teses e dissertações-Capes são instrumentos que possibilitam o acesso de informações que antes eram onerosas para o pesquisador coletar. Contudo, alguns ajustes ainda precisam ser feitos a fim de que esses instrumentos continuem possibilitando estudos inéditos, favorecendo a continuidade da pesquisa científica brasileira.
\end{abstract}

Palavras-chave: Plataforma Sucupira; Banco de teses e dissertações; Informações digitais; Pós-graduação; Brasil.

\section{INVESTIGACIONES ENTURISMO, ENELÁMBITO DE LOS PROGRAMASBRASILEÑOS DE POSGRADO EN GEOGRAFÍA:LA PLATAFORMASUCUPERAYEL BANCO DE TESESY DISERTACIONES DE CAPES COMO HERRAMIENTAS METODOLÓGICAS}

Resumen: Este relato presenta las principales potencialidades y límites de la Plataforma Sucupira y del Banco de tesis y disertaciones-Capes, en lo que se refiere al acceso de informaciones académico-gerenciales y la catalogación digital (tesis y disertaciones) a nivel de postgrado stricto sensu en En el marco de los programas brasileños de postgrado stricto sensu en geografía, defendida en febrero de 2017, en Brasil, a partir de la experiencia operacionalizada en la tesis "La digital geográfica del turismo: un análisis teórico-metodológico y conceptual de tesis y disertaciones, en el marco de los programas brasileños de postgrado stricto sensu en geografía" Universidad Federal de Río Grande del Norte. Metodológicamente, se trata de un relato evaluativo-explicativo, de sesgo cualitativo. Como principales potencialidades se destacan: el control gerencial articulado y la interfaz digital moderna y didáctica. Como límite se destaca la imposibilidad de acceso a todos los trabajos, en su totalidad para descargar. Se concluye que la Plataforma Sucupira y el Banco de tesis y disertaciones-Capes son instrumentos que posibilitan el acceso de informaciones que antes eran costosas para el investigador recolectar. Sin embargo, algunos ajustes todavía necesitan ser hechos a fin de que esos instrumentos continúen posibilitando estudios inéditos, favoreciendo la continuidad de la investigación científica brasileña.

Palabras-clave: Plataforma Sucupira; Banco de tesis y disertaciones.; Información digital; Posgrado; Brasil.

\section{RESEARCH INTOURISM INTHE GEOGRAPHY AREA OF THE BRAZILIAN POSTGRADUATE PROGRAMS' SYSTEM:THE SUCUPIRA}

\section{PLATFORM AND CAPES' DISSERTATIONSDATBASE AS METHODOLOGICALTOOLS}

\begin{abstract}
This report presents the main potentialities and limits of the Sucupira Platform and the Bank of thesis and dissertationsCapes, regarding the access of academic-managerial information and digital cataloging (theses and dissertations) at the graduate level stricto sensu no. Brazil, based on the operational expertise of the thesis "The geographic digital tourism: a theoretical-methodological and conceptual analysis of theses and dissertations, within the framework of Brazilian stricto sensu graduate programs in geography", defended in February 2017, in the Federal University of Rio Grande do Norte. Methodologically, it is an evaluativeexplanatory narrative, of qualitative bias. The main potentialities stand out: the articulated management control and the modern and didactic digital interface. As limit stands out the impossibility of access to all works, in full for download. It is concluded that the Sucupira Platform and the Bank of theses and dissertations-Capes are instruments that allow the access of information that was previously expensive for the researcher to collect. However, some adjustments still need to be made so that these instruments continue to enable unpublished studies, favoring the continuity of Brazilian scientific research.
\end{abstract}

Keywords: Sucupira Platform; Bank of theses and dissertations; Digital information; Postgraduation; Brazil.

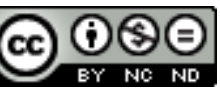

Licenciada por Creative Commons Atribuição Não Comercial / Sem Derivações/4.0/Internacional
* Doutor em Geografia (2017); Mestre em Turismo (2012) e Bacharel em Turismo (2009), com pesquisas e estudos realizados na Universidade Federal do Rio Grande do Norte (UFRN). [ christianomaranhao@gmail.com ]

** Doutor em Geografia pela Universidade Federal de Uberlândia (UFU). Professor Adjunto do Programa de Pós-graduação em Turismo (PPGTUR) e do Programa de Pós-graduação em Geografia (PPGe), ambos sediados na Universidade Federal do Rio Grande do Norte (UFRN). Universidade Federal do Rio Grande do Norte, Departamento de Geografia. Campus Universitário Lagoa Nova - CCHLA - Av. Salgado Filho Lagoa Nova. 59072-970 - Natal, RN - Brasil - Caixa-postal: 1524 [ffazevedo@gmail.com] 


\section{INTRODUÇÃO}

A produção do conhecimento científico no Brasil nunca esteve tão em evidência como se pode notar na contemporaneidade. Este cenário reflete-se diretamente na oferta de novos cursos de pósgraduação, na promoção de eventos científicos das mais diversas tipologias e temáticas e nos diversos canais de publicações que estimulam a fluidez de estudos de caráter científico com temas originais.

Atrelado à possibilidade de atuação nesses espaços de construção do saber, também se percebe certo empenho em superar determinados paradigmas, por meio do estabelecimento de um diálogo proativo entre áreas científicas distintas. Esta realidade acaba fomentando uma quantidade de pesquisas cada vez mais extensa e em constante crescimento no Brasil.

Sabe-se que esse movimento de aproximação entre áreas diferentes do conhecimento é consequência da partilha de problemas de ordem global, como a desigualdade socioeconômica e degradação ambiental, por exemplo, que codificados em questões científicas acabam demandando por uma ação conjunta entre campos disciplinares distintos (MARANHÃO, 2010; MENEGHEL, 2007). Como consequência dessa condição de produção científica conjunta, ratifica-se a necessidade por uma plataforma informacional e por uma ferramenta de catalogação digital eficientes, que possam organizar e disponibilizar dados acadêmico-gerenciais de forma ágil, de fácil acesso e reduzindo custos de forma geral.

Reconhece-se que a tecnologia a serviço da informação e de suas inúmeras possibilidades (catalogação digital) é uma tendência mundial que requer planejamento, organização, controle e treinamento de pessoal, além da manutenção dos equipamentos e o registro adequado da informação (DE FREITAS; CRUZ, 2012). Estes cuidados favorecem a otimização de tempo e espaço, colaborando com o custo do pesquisador que precisa se deslocar até a fonte original da informação; sem falar na prevenção contra danos físicos, manuseio indevido e precaução com pragas. Com efeito, os recursos tecnológicos tornaram-se uma relevante opção preventiva para a manutenção da informação e sua posterior divulgação (DASILVA, 2010).

Nota-se em face dos constantes avanços tecnológicos, que digitalizar informações e documentos tornou-se demanda imperativa para o alcance de uma divulgação ágil e para uma adequada preservação de conteúdos. Miranda (2000) diz que os anos de 1990 representaram a década em que a internacionalização das comunicações em rede obteve destaque, aumentando o uso da telefonia e de serviços interligados. Já para os primeiros anos do terceiro milênio aponta-se a consolidação da indústria da informática e dos serviços de informação, que conjugados com as telecomunicações, configuram-se no principal motor do desenvolvimento econômico, social e cultural da contemporaneidade.

No bojo dessa conjuntura, a tese "A digital geográfica do turismo: uma análise teóricometodológica e conceitual de teses e dissertações, no âmbito dos programas brasileiros de pós-graduação stricto sensu em Geografia" defendida em fevereiro de 2017 na Universidade Federal do Rio Grande do Norte (UFRN), pôde ser operacionalizada e ofertar conteúdo científico que releva a forma como a Geografia estuda o turismo, no âmbito da pós-graduação stricto sensu no Brasil. Destaca-se que os dados empíricos tratados na tese foram angariados com o suporte da Plataforma Sucupira e do Banco de teses e dissertações vinculado a Capes.

Destarte, busca-se relatar as principais potencialidades e limites identificados durante o uso da Plataforma Sucupira e do Banco de teses e dissertações-Capes, no que se refere ao acesso de informações acadêmico-gerenciais e ao serviço de catalogação digital de pesquisas (teses e dissertações) em nível de pós-graduação stricto sensu no Brasil, com base na expertise da tese mencionada.

Metodologicamente este relato caracteriza-se como avaliativo-explicativo, apresentando um viés qualitativo, e fez uso da pesquisa bibliográfica direcionada para as seções ofertadas pela Plataforma Sucupira e Banco de teses e dissertações-Capes como ferramenta técnica.

É buscando popularizar as possibilidades ofertadas pela Plataforma Sucupira e Banco de teses e dissertações- Capes com estudantes (doutorandos e mestrandos) e pesquisadores de forma geral, que este relato se justifica. Evitando que a quantidade de acessos seja incompatível com o investimento feito.

Esta exposição também se ratifica pela proposição de ajustes e sugestões, embasados no modus operandi adquirido por meio de uma atividade já concluída, fomentando o constante melhoramento das ferramentas em questão. 


\section{PLATAFORMA SUCUPIRA E O BANCO DE TESES E DISSERTAÇÕES-CAPES: FERRAMENTAS DIGITAIS DA PÓS-GRADUAÇÃO NOBRASIL}

Ao observar o percurso da história humana, notase que imersa no processo evolutivo, a tecnologia vem se desenvolvendo como uma possibilidade de preservação histórico-cultural. E dentre as múltiplas opções que os processos tecnológicos disponibilizam, a digitalização e a catalogação documental são alternativas que colaboram para o resguardo da história dos povos, favorecendo a produção intelectual e a sua continuidade.

Destaca-se que parte significativa da produção intelectual da contemporaneidade é realizada com o auxílio de ferramentas digitais. A rapidez de criação do conteúdo digital, a forma de acesso (modernas redes de comunicações e plataformas digitais) e a qualidade dos resultados são fatores determinantes que ratificam seu uso. Segundo Thomaz \& Soares (2004, p.245) “Após a explosão da produção informacional e a possibilidade de digitalização da informação, a humanidade chegou ao ponto atual, onde $90 \%$ das informações podem ser encontradas em meio digital". Logo, é oportuno expor as particularidades da Plataforma Sucupira e do Banco de teses e dissertações - Capes, ferramentas digitais que gerenciam informações, em nível da pós-graduação no Brasil.

Conforme a Coordenação de Aperfeiçoamento de Pessoal de Nível Superior - Capes (2017), a Plataforma Sucupira é uma ferramenta que surge em 2014, e que atua na coleta de informações, na realização de análises e avaliações de programas de pós-graduação, tornando-se referência para o Sistema Nacional de Pós-Graduação (SNPG). A aludida plataforma disponibiliza informações, processos e procedimentos realizados entre a Capes e o SNPG, tornando-os mais acessíveis para pesquisadores e outros agentes.

A Plataforma Sucupira é resultado da parceria entre a Capes e a UFRN, por meio de um termo de cooperação assinado em 2012, com vistas a desenvolver um sistema voltado para a coleta de informações dos programas de pós-graduação em tempo real. A fala do Dr. Rubens Maribondo, professor da UFRN, destaca o esforço pela melhoria continua da Plataforma, sublinhando o trabalho intenso e participativo com o Conselho técnico-científico da Capes. Para o referido professor, um avanço que pode ser destacado na Plataforma Sucupira é a integralização de diversos sistemas em um único banco de dados (CAPES, 2017).

Informa-se que o nome da Plataforma foi escolhido para homenagear o professor alagoano Newton Lins Buarque Sucupira (1920-2007). O renomado mestre apresentava formação em história e filosofia da educação, e foi o grande responsável pela formatação e institucionalização da pós-graduação no Brasil, por meio do Parecer Sucupira no 977 de 1965, que continha sete tópicos norteadores da pósgraduação brasileira. O modelo deixado por aludido professor há quase 50 anos, conta com singularidades que fazem com que a pós-graduação proposta no Brasil não seja uma simples cópia de um modelo de outro país (CAPES, 2017).

Na página eletrônica da Plataforma Sucupira (2017) é possível encontrar as seguintes "abas" de conteúdo diverso e que atuam na mesma base informacional. São elas:

Conheça a avaliação: consta com a avaliação feita no SNPG desde 1998, gerenciada pela Diretoria de Avaliação/Capes, e operacionalizada por consultores ad hoc. É esta demanda que assegura os níveis dos cursos de Mestrado e Doutorado no país, sendo referência para distribuição de bolsas voltadas para pesquisa;

Cursos recomendados e reconhecidos: Os cursos de mestrado profissional, mestrado acadêmico e doutorado, avaliados com nota igual ou superior a três, são aprovados pela Capes ao Conselho Nacional de Educação/MEC, ficando autorizados a expedir diplomas com validade nacional;

Coleta Capes: sistema que coleta informações dos programas de pós-graduação stricto sensu do país, sobretudo a respeito dos trabalhos de conclusão defendidos. Com o lançamento da Plataforma Sucupira, o relatório Coleta foi reformulado, e passou a ser um dos módulos da mencionada Plataforma;

Avaliação Quadrienal: é o Hotsite que divulga informações referentes à avaliação Quadrienal 2017, configurando-se como um canal de contato entre consultores, possibilitando o compartilhamento de documentos;

APCN: é o aplicativo para a proposta de novos cursos a Capes;

Minter e Dinter: espaço para tratar de assuntos referentes às turmas de Mestrado Interinstitucional (Minter) e Doutorado Interinstitucional (Dinter), 
geridas por uma IES brasileira, nas dependências de outra instituição de ensino receptora (nacional e/ou exterior);

Qualis: sistema usado para classificar a produção científica dos programas de pós-graduação, por meio de periódicos científicos. Oferta uma lista classificatória de periódicos utilizados pelos programas para divulgar sua produção, que também são avaliados segundo critérios específicos;

Dados estatísticos: Apresenta o GeoCapes (Sistema de Informações Georreferenciadas) ferramenta que oferece dados sobre a pós-graduação brasileira, a formação de professores para educação básica e outros temas relacionados à educação.

Quando se medita sobre o Banco de teses e dissertações é permitido dizer que este é um serviço disponibilizado pela Capes desde 1987, possibilitando o acesso aos resumos de teses e dissertações, defendidas nos programas brasileiros de pósgraduação. Conforme a Capes (2017), inicialmente foram disponibilizados 125.000 resumos de estudos que abarcavam o recorte temporal de 1996 a 2001.

Mediante um esforço pela ampliação, foram incluídos trabalhos defendidos a partir de 1987. Alertase que esta ferramenta é alimentada pelos dados de trabalhos de conclusão informados pelos programas de pós-graduação, por meio do relatório Coleta, que desde 2014 faz parte da Plataforma Sucupira. Ou seja, é uma ferramenta que retroalimenta o sistema geral.

Considerando as solicitações de usuários, notouse a necessidade de atualizar a base de dados produzida em SilverStream, tecnologia da Novell. Assim, desde 2013 tornou-se pública uma nova versão que passou a utilizar a tecnologia Google Search Appliance (GSA) e Hypertext Preprocessor (PHP).

Somente após essas atualizações, a ferramenta de busca passou a permitir o uso de filtros de pesquisa com base nas seguintes categorias: autor, título, instituição, nível, ano de defesa do trabalho, resumo, palavras-chave, biblioteca, linha de pesquisa, área de conhecimento, programa, agência financiadora, além da possibilidade de pesquisar em todos os campos simultaneamente (CAPES, 2017). A seguir, apresentase o percurso metodológico operacionalizado pela tese, o qual fez uso da Plataforma Sucupira e o Banco de teses e dissertações-Capes.

\section{METODOLOGIA ESTRUTURADA COM BASE NO USO DA PLATAFORMA SUCUPIRA E DO BANCO DE TESES E DISSERTAÇÕES-CAPES}

Esta exposição faz referência à seleção e estruturação dos principais procedimentos metodológicos que deram respaldo a pesquisa de tese, a qual forneceu expertise e motivação para a escrita deste relato. Antes de iniciar é válido informar algumas características que marcam a referida pesquisa, uma vez que a relação destes elementos direcionou a tomada de decisão metodológica que foi feita.

Para definir um caminho metodológico é preciso entender as relações existentes entre as partes integrantes do trabalho e suas demandas. Somente assim é que se determinam os métodos e técnicas adequadas. De acordo com Köche (2013, p. 144) quem lê o estudo "deve ter os elementos necessários para poder compreender, identificar e avaliar os procedimentos utilizados na investigação". Ciente disso expõe-se as principais características que se articularam na aludida tese, com ênfase para o suporte da Plataforma Sucupira e do Banco de teses e dissertações-Capes.

Considerando o tipo de estudo, a tese produzida caracterizou-se como exploratório-descritiva. Ao entender o turismo, enquanto campo de estudo recente, foi permitido articular as ações de explorar, descrever e explicar. Percebe-se que a necessidade de explicação do turismo está concatenada ao vasto campo científico que ainda precisa ser desvendado e descrito (VEAL, 2011).

Ao delimitar o empírico da pesquisa, a saber: os estudos (teses e dissertações) que abordam o turismo como temática de pesquisa, produzidos pelos programas brasileiros de pós-graduação stricto sensu em geografia, a caraterística qualitativa se apresenta como a alternativa majoritária no primeiro momento.

Contudo, diante do quantitativo de pesquisas identificado, a demanda por quantificá-las se tornou evidente. Constata-se então, que a tese apresentou um viés qualiquantitativo, dedicando-se à compreensão dos significados e a quantificação das informações e frequências similares. Durante a coleta do empírico é que a Plataforma Sucupira e o Banco de teses e dissertações-Capes atuaram como suporte. Relata-sea seguir, os principais episódios desta atuação.

De inicio foram definidas categorias de análise. Ou seja, para um estudo participar do empírico era preciso que ele apresentasse no título ou no resumo as 
seguintes palavras-chaves: turismo, atividade turística e fenômeno turístico. Estes termos foram selecionados a partir dos entendimentos do turismo, enquanto atividade econômica e/ou fenômeno socioespacial.

A decisão pela assistência da Capes se deu em função da sua abrangência no que tange à coleta e armazenamento de informações acadêmicas, de teses e dissertações em nível nacional, uma vez que os programas de pós-graduação não reúnem condições técnicas e orçamentárias para a operacionalização do levantamento. Assim, o pesquisador entrou em contato por e-mail com a Capes, via Secretaria do programa de pós-graduação e pesquisa em geografia da UFRN, solicitando suporte que prontamente foi atendido.

Tabela 1: Levantamento de teses e dissertações no âmbito dos programas brasileiros de pós-graduação stricto sensu em Geografia, que estudam a temática do turismo.

\begin{tabular}{|c|c|c|c|c|}
\hline \multirow[b]{2}{*}{ REGIÃO } & \multirow[b]{2}{*}{ IES } & \multicolumn{3}{|c|}{ QUANTIDADE } \\
\hline & & $\mathrm{D}$ & $T$ & Total \\
\hline \multirow{3}{*}{ Norte } & 01-Universidade Federal do Pará & 13 & - & 13 \\
\hline & 02-Fundação Universidade Federal de Rondônia. & 03 & - & 03 \\
\hline & Total de Trabalhos-Região Norte & 16 & - & 16 \\
\hline \multirow{8}{*}{ Nordeste } & 03-Universidade Federal da Bahia & 26 & - & 26 \\
\hline & 04-Universidade Federal do Ceará & 21 & 02 & 23 \\
\hline & 05-Universidade Estadual do Ceará & 35 & - & 35 \\
\hline & 06-Universidade Federal da Paraíba & 07 & - & 07 \\
\hline & 07-Universidade Federal de Pernambuco & 32 & 03 & 35 \\
\hline & 08-Universidade Federal do Rio Grande do Norte & 25 & - & 25 \\
\hline & 09-Fundação Universidade Federal de Sergipe & 15 & 10 & 25 \\
\hline & Total de Trabalhos-Região Nordeste & 161 & 15 & 176 \\
\hline \multirow{6}{*}{ Centro-oeste } & 10-Universidade de Brasília & 12 & - & 12 \\
\hline & 11-Universidade Federal de Goiás & 28 & 04 & 32 \\
\hline & 12-Fundação Universidade Federal de Mato Grosso do Sul & 15 & - & 15 \\
\hline & 13-Universidade Federal da Grande Dourados & 04 & - & 04 \\
\hline & 14-Universidade Federal de Mato Grosso & 21 & - & 21 \\
\hline & Total de Trabalhos-Região Centro-Oeste & 80 & 04 & 84 \\
\hline \multirow{13}{*}{ Sudeste } & 15-Universidade Federal de Minas Gerais & 37 & 02 & 39 \\
\hline & 16-Universidade Federal de Uberlândia & 24 & 04 & 28 \\
\hline & 17-Pontifícia Universidade Católica de Minas Gerais & 11 & 03 & 14 \\
\hline & 18-Universidade Federal do Rio de Janeiro & 16 & 16 & 32 \\
\hline & 19-Universidade Federal Fluminense & 09 & 05 & 14 \\
\hline & 20-Universidade Estadual do Rio de Janeiro & 24 & - & 24 \\
\hline & 21-Pontifícia Universidade Católica do Rio de Janeiro & 02 & - & 02 \\
\hline & 22-Universidade de São Paulo & 71 & 54 & 125 \\
\hline & 23-Universidade Estadual de Campinas & 22 & 08 & 30 \\
\hline & 24-Pontifícia Universidade Católica de São Paulo & 04 & - & 04 \\
\hline & 25-Universidade Estadual P. Júlio de Mesquita Filho & 32 & 34 & 66 \\
\hline & 26-Universidade Federal do Espírito Santo & 01 & - & 01 \\
\hline & Total de Trabalhos-Região Sudeste & 253 & 126 & 379 \\
\hline \multirow{10}{*}{ Sul } & 27-Universidade Federal do Paraná & 34 & 13 & 47 \\
\hline & 28-Universidade Estadual de Londrina & 10 & - & 10 \\
\hline & 29-Universidade Estadual de Maringá & 12 & 01 & 13 \\
\hline & 30-Universidade Estadual de Ponta Grossa & 05 & - & 05 \\
\hline & 31-Universidade Estadual do Oeste do Paraná & 02 & - & 02 \\
\hline & 32-Universidade do Rio Grande do Sul & 13 & 04 & 17 \\
\hline & 33-Universidade Federal de Santa Maria & 10 & - & 10 \\
\hline & 34-Universidade Federal do Rio Grande & 01 & - & 01 \\
\hline & 35-Universidade Federal de Santa Catarina & 44 & 10 & 54 \\
\hline & Total de Trabalhos-RegiãoSul & 131 & 28 & 159 \\
\hline \multicolumn{2}{|l|}{ Total Geral } & 641 & 173 & 814 \\
\hline
\end{tabular}

Fonte: Dados da Pesquisa, 2017. 
A Capes enviou um arquivo de Excel contendo 814 resumos de estudos geográficos (teses e dissertações) que se dedicaram ao turismo, em nível de todos os programas de pós-graduação em geografia do Brasil. Com isso, foi possível confeccionar a Tabela 1 com informações sobre: a produção de estudos por região, por IES, por tipologia de pesquisa (tese ou dissertação), por orientador e data de defesa.

Feita a primeira categorização dos dados, a etapa seguinte foi realizar um cálculo de amostra, que além de garantir dinamicidade para a pesquisa, possibilitou que a seleção abarcasse todo território nacional, e similarmente, todos os programas de pósgraduação em geografia validados pela Capes no ano de 2016. Paralelamente, se coletava dados sobre cada programa de pós-graduação identificado, a saber: histórico e datas de fundação, áreas de concentração, linhas de pesquisa, conceito capes, cursos stricto sensu e cursos latu sensu, a partir da base de dados da Plataforma Sucupira.Com estas etapas finalizadas, restava a coleta dos trabalhos selecionados.

No primeiro momento, os trabalhos eram pesquisados pelos títulos, no Banco de teses e dissertações-Capes, mas somente alguns eram localizados, e mesmo assim não disponibilizavam as versões finais. O cenário exigiu criatividade. Então, os trabalhos forma pesquisados na rede de computadores; Encaminharam-se e-mails para as secretarias das pós-graduações e/ou para os pesquisadores, solicitando os estudos diretamente aos autores. Mesmo com essa dificuldade, a lista do Banco de teses e dissertações da Capes foi um elemento essencial e norteador para as estratégias tomadas. Concluída a coleta, iniciou-se a ordenação do material visando sua análise, para que sequencialmente fosse permitido gerar os resultados amparados por uma base metodológica coerente.

A análise dos dados foi realizada por meio do resumo, sumário, introdução, objetivos, procedimentos metodológicos e conclusões. A escolha dos itens alinhou-se às normativas da Associação Brasileira de Normas Técnicas (ABNT), que apontam especificidades para cada um. Como técnica para esta fase da pesquisa selecionou-se a técnica da Análise de Conteúdo (BARDIN, 2004). Ainda é importante destacar que a análise do objetivo específico B, foi utilizada duas ferramentas digitais de código aberto, a saber: software Pajek e ferramenta Wordle.

\section{POTENCIALIDADES E LIMITES, QUANTO AO ACESSO DE INFORMAÇÕES ACADÊMICO-GERENCIAIS E A CATALOGAÇÃO DIGITAL DE PESQUISAS, DA PLATAFORMA SUCUPIRA E DO BANCO DE TESES E DISSERTAÇÕES-CAPES}

Compreende-se que o estudo, independente da metodologia, acabou alcançando metas e atuando diante de algumas limitações, que solicitaram senso lógico para a resolução dos problemas que apareciam. O centro do debate deste relato de experiência refere-se às análises específicas das demandas relacionadas ao acesso de informações acadêmico-gerenciais e à catalogação digital de pesquisas, coletadas junto à Plataforma Sucupira e ao Banco de teses e dissertações-Capes. Logo, expõemse os principais alcances, limitações e proposições.

Como se tratava de estudos (teses e dissertações) produzidos num recorte temporal, a priori não determinado, e dotado de um amplo escopo nacional que concentra todos os programas de pós-graduação em geografia do Brasil, se fazia necessário que os bancos de dados selecionados fornecessem um suporte relevante diante do cenário constituinte da pesquisa. Só por isso, já se pontua que tanto a Plataforma Sucupira quanto o Banco de teses e dissertações-Capes possibilitaram que os processos metodológicos pudessem ser efetuados com êxito.

No que tange a Plataforma Sucupira relata-se que ela permitiu a coleta das informações acadêmico-gerenciais referentes aos programas de pós-graduação, a saber: datas de fundação, histórico, cursos, conceitos, áreas de concentração, linhas de pesquisa entre outros informes. Enquanto isso, o acesso ao Banco de teses e dissertações-Capes foi direcionado para a busca e coleta dos estudos de tese e dissertação.

Assim, como um dos principais resultados positivos ofertado pela Plataforma Sucupira, tem-se o amplo acesso de informações acadêmico-gerenciais atualizadas, em nível da pós-graduação no Brasil. Principalmente quando se comprara com a conjuntura limitada encontrada na maioria das bibliotecas digitais, de cada programa de pósgraduação em geografia no Brasil. Onde se verificou ineficiência de atualização de dados básicos, como os cadastrais por exemplo.

Outro aspecto positivo diz respeito ao layout digital da Plataforma Sucupira, que responde as necessidades imediatas do usuário, disponibilizando 
processos simples e ferramentas didáticas que dinamizam o tempo, facilitam o acesso e a coleta de informações. Somado a isto, é possível mencionar ainda a facilidade de acionar em um mesmo local, diversos serviços concatenados, em nível da pósgraduação brasileira. Como também o pronto atendimento para com as dúvidas e encaminhamentos enviados à equipe de servidores da Capes.

No que se refere ao Banco de teses e dissertações-Capes é possível apontar seu melhoramento no que se refere ao incremento de seus filtros de pesquisa. Os recursos utilizados apresentam uma linguagem simplificada, sem perder o valor da informação. Todo este desdobramento impacta diretamente, no fomento de inúmeras possibilidades de pesquisa científica que pode usar dessas informações, fazendo o devido cruzamento de dados.

Destaca-se que no início da estruturação da pesquisa de tese, base para este relato, o Banco de teses e dissertações-Capes não contava com essa concatenação de inúmeros filtros, limitando a prestação do serviço, sinalizando para a necessidade de melhoramento, fato que só ocorreu recentemente.

Identifica-se no Banco de teses e dissertaçõesCapes a necessidade de ampliação da catalogação digital de trabalhos defendidos por cada programa de pós-graduação. Visto que o controle destes trabalhos já existe e é repassado para Capes, por meio dos relatórios. Esta dificuldade replica-se pelas bibliotecas digitais dos referidos programas, as quais permanecem alheias a esta demanda importante. Destaca-se uma defasagem com relação à inserção de trabalhos defendidos no âmbito dos programas de pós-graduação, que antecedem a década de 1990, por exemplo.

Os resultados sinalizam para a limitação mais expressiva desta experiência, a dificuldade em localizar os trabalhos selecionados, na íntegra, para download. Uma vez que parte dos programas consultados não disponibiliza de todos os trabalhos listados na biblioteca digital e a maioria disponibilizam apenas dos resumos. E o próprio Banco de teses e dissertações-Capes não possibilita o download para todos os trabalhos pesquisados. Sobretudo para os trabalhos datados antes de 2013, precedentes à Plataforma Sucupira.
Associado a isto, aponta-se que mesmo apresentando uma listagem de trabalhos defendidos entre os anos de 1987 a 2012, o Banco de tese e dissertações-Capes disponibiliza somente detalhes referentes ao nome do autor, título do trabalho, data e ano de defesa, número de páginas, nome do programa, da instituição e da biblioteca depositária. Quando se refere aos trabalhos datados após 2013, verifica-se uma ampliação considerável dos dados disponíveis. Para estes trabalhos já é possível ter acesso: resumo, abstract, área de concentração, linha de pesquisa, banca examinadora, e de forma fundamental, o arquivo digital da pesquisa, na íntegra, para download.

Há de convir que se existisse um recorte temporal mais amplo, com relação à catalogação digital de teses e dissertações e à oferta dos trabalhos na íntegra, para downloads, permitiria a economia de tempo e recurso para a coleta de informações relevantes para os estudos, além de ser uma maneira de preservar a memória dos trabalhados datados de períodos anteriores. A partir disso, é possível dimensionar a dificuldade que foi para operacionalizar a pesquisa de tese, uma vez que sua amostra probabilística identificou 49 pesquisas, entre teses e dissertações, espalhadas por 35 IES nacionais.

Ainda sobre o processo de coleta, é importante relatar que em alguns sites das IES não era possível selecionar sequer o programa de pós-graduação específico, antes de efetivar a busca geral, revestindo a coleta de maior cuidado na verificação dos dados que não estavam expostos no primeiro plano da investigação. Não havia filtros de pesquisa suficientes para a efetivação coerente da demanda.

Por entender que este relato pode vir a servir como parâmetro para estudos futuros, oriundos de outras áreas temáticas e/ou campos do conhecimento distintos, é que se destacam algumas proposições: Entende-se, que somente a partir da devida estruturação e exposição digital dos dados que tratam do cenário da pós-graduação brasileira, com base nas experiências dos usuários, é que se torna possível impulsionar pesquisas em diferentes escalas de análise.

No que se refere aos dados acadêmicogerenciais, indica-se que seria bem-vinda à informação que expusesse as parcerias internacionais e nacionais em vigor, as principais bases e grupos de pesquisa e o contato de seus coordenadores, os projetos de extensão em destaque, os processos 
seletivos para professores e discentes entre outros informes. Essas informações até constam nos sites de alguns programas de pós-graduação, mas nem sempre com o nível informacional necessário, o que restringe a informação a um inexpressivo público interno.

E quando se pensa em proposições para a ferramenta do Banco de tese e dissertações-Capes, de imediato vem à indicação do melhoramento relacionado à catalogação digital dos trabalhos e a sua atrelada disponibilização para downloads, ao menos dos trabalhos datados a partir de 1987.

Simultaneamente, compreende-se que esta demanda não seria a mais fácil de operacionalizar, uma vez que paralelo à ação de catalogação digital das pesquisas anteriores ao ano de 2013 , haveria a demanda de atualização com pesquisas recentes. Apesar disso, e visando à preservação da história da pós-graduação no Brasil, tal esforço é válido, mesmo que para longo prazo.

Espera-se então, que a Plataforma Sucupira e o Banco de teses e dissertações-Capes passem a gerenciar e disponibilizar, de forma totalitária e integrada, todas as informações, interfaces, produtos e desdobramentos que formatam a conjuntura da pós-graduação no Brasil. Empenho que daria suporte determinante para muitos pesquisadores.

\section{REFLEXÕES FINAIS}

Os fatos apresentados neste relato indicam, mesmo diante de alguns desafios operacionais, que a Plataforma Sucupira e o Banco de teses e dissertações-Capes possuem um papel basilar no cenário da pós-graduação no Brasil. Uma vez que gerenciam um montante expressivo de informações, que se bem categorizadas, possibilitam a tomada de decisão sensata, seja em nível gerencial, operacional ou científico.

Reconhece-se que a opção de ofertar um serviço sinérgico, que congrega diversos órgãos, setores, ações e demandas, parece ser o mais coerente, quando analisado em face da conjuntura da pós-graduação no Brasil.

Diante do esforço pelo melhoramento da Plataforma Sucupira e do Banco de teses e dissertações-Capes, fica patente que a dificuldade mais expressiva neste contexto é a digitalização totalitária da produção (teses e dissertações) da pós- graduação no Brasil, e a sua posterior disponibilização via downloads. Evidencia-se que esta ação favorece a otimização dos espaços das bibliotecas físicas das universidades brasileiras.

Paralelamente, esta ação de digitalização dos trabalhos da pós-graduação no Brasil passaria a ofertar uma base significante de dados que poderiam ser usados como categorias comparativas de cenários estudados em períodos distintos. Uma dentre várias perspectivas que podem ser fomentadas, como alicerce dos objetivos das pesquisas que virão.

Desse modo, ratifica-se que a Plataforma Sucupira e o Banco de teses e dissertações - Capes assume a função de "guardiões" da memória acadêmica do Brasil, entendidos como ferramentas que possibilitam a continuidade de estudos, por onde desemboca novas aplicações teóricas, metódicas e técnicas, destacando o serviço de utilidade pública inerente a Capes.

Ao fazer a correlação entre as questões operacionais vinculadas à Plataforma Sucupira e ao Banco de teses e dissertações da Capes e os resultados da tese, relata-se os principais alcances teóricos. No primeiro momento, destaca-se que o expressivo quantitativo de 814 pesquisas geográficas que fazem uso da temática do turismo foi motivo de grata surpresa, uma vez que se observa na academia certo descrédito e falta de prestigio acadêmico quando se fala na pesquisa sobre o turismo. Contrário ao cenário, o montante dos dados coletados indica um desvio padrão relevante. $\mathrm{E}$, por conta disso, a busca pelo entendimento de como o turismo é estudado pela Geografia recebeu ânimo novo.

Pelo cenário que o empírico coletado expôs, os dados atestam uma concentração de estudos geográficos (teses e dissertações) sobre o turismo na região sudeste, em função da expressiva concentração de programas de pós-graduação e cursos (mestrado e doutorado) em Geografia, avaliados pelo alto desempenho, segundo critérios da Capes. Figurando na segunda posição, aparecem as regiões nordeste e sul, que se alternam na viceliderança, seguidas pela região centro-oeste, e por último, a região norte por conta de inexpressivos números, reflexo da quantidade insuficiente de programas e da atrelada quantidade de estudos em torno da temática do turismo.

Ainda sobre o empírico coletado, tem-se que a maioria dos objetos de estudos faz alguma relação 
com a localização geográfica do referido programa, indicando a interferência do cotidiano vivido, na formulação dos questionamentos dos pesquisadores. Essa fala não é uma regra engessada, mas foi identificada com certa frequência.

Cabe destacar que, dentre os programas brasileiros de pós-graduação em geografia que abordam o turismo como temática, os programas vinculados à Universidade Federal de Minas Gerais (UFMG) e à Universidade Estadual de Londrina (UEL) destacam-se por apresentarem a temática do turismo de forma mais evidente, em seus campos de atuação, seja por meio da oferta do curso de especialização "Turismo e Desenvolvimento Sustentável" por parte da UFMG, seja pelos incentivos promovidos em torno da temática do "Turismo Rural" na UEL.

Perante a exploração do conteúdo coletado é possível verificar ainda que em alguns programas, promove-se uma perspectiva de análise direcionada para "Geografia Física", fator que acabou fragilizando uma possível aproximação das questões sobre o turismo, que por si só, são dotadas de significados sociais. Já com relação a outros programas, nota-se que mesmo não fazendo referência ao turismo, eles apresentam assuntos que são recorrentes nos debates turísticos, a saber: globalização, política pública, sustentabilidade, entre outros. Fato que pode vir a facilitar certa aproximação para os anos que seguem.

Por todo o exposto, há que se considerar o entendimento que se quis trazer quando se optou pelo título "A Digital Geográfica do Turismo". Como acadêmico graduado no curso de turismo, reconheço os avanços do turismo, enquanto tema de pesquisa, ao passo que também atesto - "sinto na pele"- seu tenro e instável alicerce. E justamente por ter sido cooptado tão recentemente pelo campo científico, observo-o imbuído por revigorar seus esforços, a fim de dispor de conteúdos que possibilitem a explicação do empírico vivenciado.

Baseado nas análises tem-se que o turismo é entendido pela Geografia, predominantemente, como uma atividade econômica e vetor de produção do capital, com expressivas repercussões na dimensão espacial. É nítida a percepção do turismo como estratégia para promover o lucro, garantindo a capacidade de reprodução ampliada do sistema capitalista.
De posse desse entendimento, a ciência geográfica passa a identificar o turismo nas paisagens, sobretudo naturais, revelando que a atividade do turismo brasileiro acontece em boa medida, pela utilização dos recursos naturais, os quais centralizam as motivações que promovem os deslocamentos turísticos. E a partir dessa atuação particular nas paisagens, é que o turismo acaba transformando-as em "produtos" a serem comercializados, e por isso mediados pelo sistema capitalista.

Obedecendo a sequência da análise, informa-se que as principais teorias habilitadas pela Geografia para gerir a compreensão da práxis do turismo brasileiro, estão alinhadas com as conjunturas por onde o turismo se desenvolve, ou seja, variam pelo tratamento do espaço geográfico, pelo viés do consumo, pelos danos causados nos ambientes naturais, pela busca por sustentabilidade, pela consolidação da instância social, e, sobretudo, pelo viés econômico.

Sobre o método de abordagem mais empregado pelos estudos coletados, destaca-se o método dialético como o mais frequente nas análises geográficas sobre o turismo, quer compreendido como prática social ou como atividade econômica.

A razão para esse protagonismo origina-se na qualidade da produção geográfica brasileira das últimas décadas, assentada em grande parte, na (re) leitura de Marx e na superação de velhos paradigmas metodológicos associados ao positivismo e ao quantitativíssimo, principalmente. Reconhece-se que o movimento de renovação do pensamento geográfico brasileiro é o "pano de fundo" sobre o qual emerge o pluralismo metodológico que caracteriza a Geografia crítica, mas do interior desse pluralismo, o materialismo histórico e dialético é o método que ganhou maior proeminência na Geografia brasileira.

Conclui-se que é perceptível o pouco esforço teórico e metodológico da Geografia para compreender o turismo, enquanto fenômeno complexo, seja ao longo da história, seja na contemporaneidade. E a pós-graduação em Geografia no Brasil tem o enorme desafio de contribuir para o desvendamento da realidade espacial brasileira do passado e da atualidade, dedicando-se a temas e situações geográficas que possibilitem avanços na sua produção do conhecimento, a exemplo do turismo, agronegócio, indústria, comércio, mineração, entre outros assuntos. 
Pensando assim, o tema do turismo não precisa ser mais nem menos importante que tantos outros temas que demandam a produção de um conhecimento especializado, teórica e metodologicamente fundamentado. Ele, juntamente com os demais temas, só precisa ser investigado pela Geografia, em função da contribuição que pode fornecer à produção do conhecimento, no sentido de se vislumbrar um processo de construção de uma sociedade mais justa no futuro breve.

Sobre a Plataforma Sucupira e o Banco de Teses e dissertações da Capes é oportuno ainda ressaltar que não se pretendeu exaurir o assunto neste relato, mas dar o passo inicial em busca de uma maior discussão em torno do contexto debatido. Buscou-se estimular a necessidade de mais análises, inseridas na perspectiva dos usuários (pesquisadores), com o intuito de relatar e estruturar como está o atual cenário da pós-graduação no Brasil, por meio das possibilidades informacionais ofertadas pela Plataforma Sucupira e Banco de teses e dissertaçõesCapes.

\section{REFERÊNCIAS}

Bardin, L. (2004). Análise de Conteúdo. Edições 70. Lisboa, Portugal.

BRASIL, Ministério da Educação (2014). Novo desenho garante melhorias à Plataforma Sucupira da Capes. Disponível em:

http://portal.mec.gov.br/component/tags/tag/3599

5.> Acesso em 25 de julho de 2017.

CAPES, Coordenação de Aperfeiçoamento de Pessoal de Nível Superior (2014). Plataforma Sucupira. Disponível em:

http://www.capes.gov.br/avaliacao/plataformasucupira>. 01 abril, 2014. Acesso em 25. Julho. 2017. ; (2017, May, 08) Plataforma Sucupira ganha novo layout. Disponível em:< http://www.capes.gov.br/component/content/articl e/36-salaimprensa/noticias/8383-plataformasucupira-ganha-novo-layout>. Acesso em 25 de julho de 2017.
; (2017) Banco de Teses e Dissertações. Disponível em: < http://bancodeteses.capes.gov.br/bancoteses/\#!/>. Acesso em 25 de Julho de 2017.

Corrêa, R. L. (2003) Análise crítica de textos geográficos: breves notas. Revista do departamento de geografiaUERJ. №14. p. 7-18.

Da Silva, G. P. (2010). A Importância dos Acervos Digitais. Revista Brasileira de Arqueometria, Restauração e Conservação - ARC - Vol. 3 - Edição Especial-CICRAD. Editora AERPA.

Ferreira, M. (2006). Introdução à preservação digital: Conceitos, estratégias e actuais consensos. Guimarães (Por). Escola de Engenharia da Universidade do Minho.

Freitas, J.D; Cruz, K.R. (2012, jan.). A importância da digitalização dos documentos memoriais da Biblioteca Central Zila Mamede (BCZM). Anais... Encontro Regional de Estudantes de Biblioteconomia - Informação e Sociedade: a importância da Biblioteconomia no processo de preservação da memória documental.

GIL, A. C. (2007). Métodos e técnicas de pesquisa social. 5. ed. São Paulo: Atlas.

Köche, J. C. (2013). Fundamentos de metodologia científica. Teoria da ciência e iniciação à pesquisa. 32 ed. Petrópolis, Rio de janeiro: Vozes.

Maranhão, T. de P. A. (2010). Produção interdisciplinar de conhecimento científico no Brasil: temas ambientais. Revista Sociedade e Estado, v. 25, n. 3 set./dez. 2010.

Meneghel, Stela M et al. (2007). Produção de conhecimento no contexto brasileiro: perspectivas de instituições emergentes. Atos de Pesquisa em Educação - PPGE/ME FURB, v 2, n. 3, p. 444-460, set./dez.

Miranda, A. L. C. de, (2000). Os conteúdos e a sociedade da informação no Brasil. DataGramaZero, Revista de Ciência da Informação.

Thomaz, K. P.; Soares, A. J. (2004). A preservação digital e o modelo de referência Open Archival Information System (OAIS). DataGramaZero: Revista de Ciência da Informação. v. 5, n. 1 . Disponível em: <http://www.dgz.org.br/fev04/Art 01.htm>. Acesso em 7 jun. 2004.

Veal, A. (2011). Metodologia de pesquisa em lazer e turismo. [Tradução: Gleice Guerra; Mariana Adligue]. São Paulo: Aleph. Série turismo. 